\title{
Managing Hazardous Municipal Wastewater: A Membrane- Integrated Hybrid Approach for Fast and Effective Treatment in Low Temperature Environment
}

\author{
Parimal Pal', Iyman Abrar and Ramesh Kumar \\ Environmental and Membrane Technology Laboratory, Department of Chemical Engineering, National \\ Institute of Technology Durgapur, 713209, India
}

\begin{abstract}
Protection of natural water resources like lakes from the onslaught of hazardous municipal wastewater is often a challenge particularly in the cold regions. For treatment of enormous quantity of municipal wastewater, biological treatment is normally adopted but high COD (Chemical Oxygen demand) of such wastewater turns biological treatment slow and difficult. At low temperature environment, effective treatment of such municipal wastewater becomes extremely difficult due to weakened microbial activities. The present study was carried out with a hybrid approach comprising chemical treatment and membrane separation under psychrophilic conditions. Well-known Fenton's treatment was adopted under response surface optimized conditions that helped recovery of nitrogen and phosphorus nutrients as value-added struvite fertilizer or magnesium ammonium phosphate $\left(\mathrm{NH}_{4} \mathrm{MgPO}_{4} \cdot 6 \mathrm{H}_{2} \mathrm{O}\right)$. The optimal COD removal was found to be $96 \%$ at a low temperature of $15^{\circ} \mathrm{C}$ and $\mathrm{pH}$ of 6.3 using $\mathrm{Fe}^{2+} / \mathrm{H}_{2} \mathrm{O}_{2}$ ratio of 0.10 and of $\mathrm{H}_{2} \mathrm{O}_{2} 1.9 \mathrm{~g} / \mathrm{l}$ with reaction time of $2 \mathrm{~h}$. Down-stream purification of the struvite-free water by microfiltration and nanofiltration largely fouling-free flat sheet cross flow membrane modules ultimately turned the treated water reusable through reduction of dissolved solids, conductivity and salinity.
\end{abstract}

Keywords: Municipal wastewater, Low temperature treatment, Central composite design, Fenton's treatment, membrane filtration.

\section{INTRODUCTION}

Natural water bodies have been subjected to severe environmental degradation mainly due to urbanization, discharge of dirty sewage water, industrial wastewater and agricultural run-off. Even the famous Dal lake of Kashmir one of the most beautiful lakes of world could not escape such onslaught. Poorly treated municipal wastewater with high load of nitrogen and phosphorous often leads to eutrophication of natural water bodies. Improper treatment of such municipal wastewater can often be traced to difficulty of treating complex wastewater in conventional methods particularly at low temperatures. Biological treatment of enormous quantity of municipal wastewater is often a standard choice being cheap. However, conventional biological treatment is quite slow at low temperature due to impeded microbial activities and dramatic increase volume of wastewater with ever increasing population and urbanization aggravates the problem further.

Traditionally, activated sludge process (ASP) has been widely used for treatment of municipal wastewater mainly exploiting its capability of treating large volume of wastewater in a compact plant with reasonably high degree of removal efficiency.

*Address correspondence to this author at the Environmental and Membrane Technology Laboratory, Department of Chemical Engineering, National Institute of Technology Durgapur, 713209, India; Tel: +91 343 2755955; Mob: +91 943446950; Fax: +91343 2547375; E-mail: parimalpal2000@yahoo.com, ppal.nitdgp@gmail.com
However, it has high operational and maintenance cost [1]. Moreover, conventional activated sludge process fails to remove the pathogenic microorganisms and hence treated water can neither be discharged directly into natural water bodies without further treatment nor can be reused [2]. Sequencing batch reactor (SBR) is one of the most promising and feasible modification of activated sludge process which is usually employed for biological nutrient removal [3]. The SBR also requires high level of sophistication of timing and controls [4]. Membrane Bioreactors (MBR) have also been gaining importance over the recent years by virtue of their capability of producing high quality of effluents, reduced system volume, higher mixed liquor suspended solids and perfect sludge retention time control [5]. High removal efficiency (above $85 \%$ ) has been reported in this treatment of wastewater high with nitrogen, phosphorous and COD [6]. However, membrane fouling and relatively higher overall cost are the main drawbacks of this system [7]. Mixed liquor suspended solids, colloidal and dissolved organic matters primarily contribute to membrane fouling [8] where properties of the membrane themselves play a very strong role.

The biological treatment of wastewater is quite time-consuming and has the disadvantages huge sludge generation. The chemical treatment on the other hand is quite fast. Low cost adsorbents are being used for the removal of organic matter from wastewater. The 
mixed adsorbent carbon and commercial activated carbon showed COD and BOD removal of COD and BOD of more than $95 \%$ [9]. The coagulation process has higher removal efficiency of COD and suspended solids. Optimization of alum coagulation process has been reported for successful removal (85\%) of COD and TSS at room temperature [10]. A combined pretreatment unit for municipal wastewater in which coagulation, flocculation and sedimentation were carried out resulted in removal of TSS, COD and phosphorous by $83 \%, 65 \%$ and $76 \%$ respectively [11]. Fenton's treatment is gaining attention as an advanced oxidation technology and is readily employed to treat wastewater as it is much cheaper and easier to operate than other oxidation techniques [12]. It is mainly used when higher reduction of COD is required. It is being successfully used in treatment of industrial wastewater, pharmaceutical wastewater, olive oil mill wastewater, bamboo industry wastewater, landfill leachate etc. The main advantage of Fenton's reagent is that no energy is required to activate $\mathrm{H}_{2} \mathrm{O}_{2}$ and hence it is a cheap source of hydroxyl radicals [13]. Fenton's process when coupled with SBR for treating bamboo industry wastewater was found to have COD removal efficiency of $86-97 \%$ [14]. Optimization of various parameters overcoming their mutual interactions can be successfully done by using response surface methodology (RSM). It uses experimental design such as central composite design (CCD) to fit the model by least square [15]. The competence of the model is then verified using analysis of variance (ANOVA). Hence the present study uses Fenton's treatment for the removal of COD from municipal wastewater. The recovery of struvite (magnesium ammonium phosphate) as a fertilizer from wastewater makes the treatment of wastewater more economical. The $\mathrm{NH}_{4}{ }^{+}-\mathrm{N}$ and phosphorous recovery to the tune of $40-90 \%$ and $30 \%$ respectively has been reported [16]. The optimization of struvite precipitation in swine wastewater resulted in more than $90 \%$ phosphorous recovery [17]. Batch experiments carried out for the recovery of $\mathrm{NH}_{4}{ }^{+}-\mathrm{N}$ as struvite could reduce $98 \%$ of $\mathrm{NH}_{4}{ }^{+}-\mathrm{N}$ from simulated wastewater [18]. A membrane integrated hybrid treatment scheme for the treatment of industrial wastewater resulted in more than $95 \%$ of $\mathrm{NH}_{4}{ }^{+}-\mathrm{N}$ recovery as struvite [19]. Nanofiltration falls between ultrafiltration and reverse osmosis and has successfully being used for reclaiming the wastewater [20]. The reuse of municipal wastewater for various purposes such as agricultural and industrial water source has reduced the load on natural water resources [21].
Integration of downstream micro and nanofiltration in cross flow membrane modules with chemical precipitation following optimized Fenton's method in treatment of municipal wastewater is yet to be reported in the literature despite potential of high degree of purification of municipal wastewater along with production of by-product struvite fertilizer in an economically attractive hybrid process. The present hybrid treatment approach is expected to fill this technology gap with promise of fast treatment in low temperature environment.

\section{MATERIALS AND METHODS}

\subsection{Materials}

All the chemicals used were of reagent grade and were used directly without further purification. The chemicals such as ammonium chloride, hydrogen peroxide, iron (II) sulphate, phenol, sodium nitrate and sucrose were obtained from Merck (Germany). All the solutions were prepared by using deionized water from the Milli-Q purification system (USA). The thin film composite polyamide nanofiltration membranes were purchased from Sepromembranes Inc.(USA) and poly vinylidene fluoride (PVDF) microfiltration membranes from Membrane Solution respectively (USA).

\subsection{Wastewater Sampling and Characterization}

Sample municipal wastewater was collected from the sewage treatment plant Laam, Srinagar, Jammu and Kashmir, India. After characterization of the collected sample water, subsequent experimental investigations were conducted with water simulated with characteristics of the wastewater that makes its way into the Dal Lake. The simulated wastewater was prepared by tap water amended with stock solution of disodium hydrogen phosphate, ammonium chloride, sodium nitrate and sodium carbonate. No microelements were added as they were already present in tap water. The characterization of the wastewater is presented in Table $\mathbf{1 .}$

\subsection{Experimental Set-Up}

The schematic diagram for the hybrid process is shown in Figure 1. The experimental setup consists of a series of continuous stirred tank reactors (CSTR). Reactor levels are adjusted to allow water flow under gravity from the first unit to the last unit without use of additional pumps in between. The first CSTR is Fenton treatment unit in which ferrous sulphate heptahydrate and hydrogen peroxide are added. This is followed by a 
Table 1: Characteristics of Municipal Wastewater before after Treatment

\begin{tabular}{|c|c|c|c|c|}
\hline Parameter & $\begin{array}{l}\text { Influent concentration } \\
(\mathrm{mg} / \mathrm{l})\end{array}$ & $\begin{array}{l}\text { After chemical } \\
\text { treatment (mg/l) }\end{array}$ & $\begin{array}{l}\text { After membrane } \\
\text { separation (mg/l) }\end{array}$ & $\begin{array}{c}\text { Irrigation water } \\
\text { standard }[20](\mathrm{mg} / \mathrm{l})\end{array}$ \\
\hline $\mathrm{NH}_{4}^{+}-\mathrm{N}$ & 60 & $\mathrm{BDL}^{*}$ & BDL & $<5$ \\
\hline Phosphate & 70 & BDL & BDL & $<2$ \\
\hline TIC & 50 & 48 & 10 & - \\
\hline COD & 400 & 20 & 11 & $<250$ \\
\hline TDS & 2350 & 4320 & 561 & $<2000$ \\
\hline Conductivity $(\mathrm{mS} / \mathrm{cm})$ & 0.70 & 4.47 & 0.52 & $<3$ \\
\hline Salinity & 4.2 & 6.3 & 0.26 & $<1.94$ \\
\hline $\mathrm{pH}$ & $7.0-8.0$ & 9.0 & 7.5 & $6.0-8.5$ \\
\hline
\end{tabular}

*below detection limit.

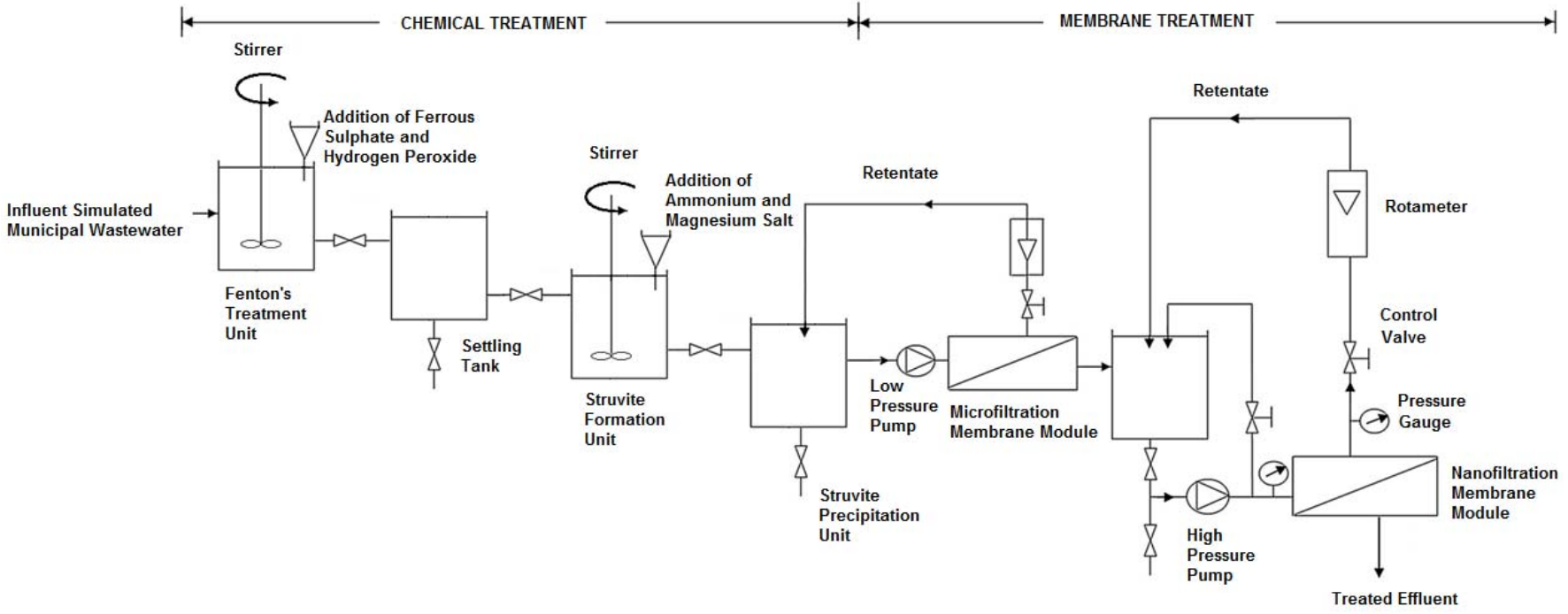

Figure 1: Schematic Diagram of hybrid treatment process for municipal wastewater.

settling tank where the sludge is removed. Then another reactor is used for struvite formation. This is followed by a flat sheet cross flow microfiltration membrane module for separation of struvite. Cross flow modules are less prone to fouling as compared to hollow fiber and spiral wound membrane modules. Finally, flat sheet cross flow nanofiltration membrane modules are used for the removal of salts produced during struvite formation. Temperature of the feed tank was maintained constant by temperature controller. The effective filtration area was $100 \mathrm{~cm}^{2}$. The $\mathrm{pH}$ of the system was maintained by $5 \mathrm{M} \mathrm{NaOH}$ and $\mathrm{HCl}$ solutions.

\subsection{Experimental Procedure}

The municipal wastewater was first subjected to chemical treatment consisting of two steps. Initially the wastewater was treated with Fenton's reagent
( $\mathrm{FeSO}_{4} \cdot 7 \mathrm{H}_{2} \mathrm{O}$ and $\mathrm{H}_{2} \mathrm{O}_{2}$ ) for $\mathrm{COD}$ removal. Fenton's process was optimized using response surface methodology (RSM) of Design Expert Software (version 8.0). The central composite design (CCD) was used for the four parameters namely $\mathrm{pH}$, temperature, $\mathrm{Fe}^{2+} / \mathrm{H}_{2} \mathrm{O}_{2}$ and $\mathrm{Fe}^{2+}$. First batch experiments were carried out for optimization of Fenton's reagents in a $250 \mathrm{ml}$ conical flask containing $100 \mathrm{ml}$ wastewater in incubator and shaker set at $160 \mathrm{rpm}$ and operating temperature of $15^{\circ} \mathrm{C}$ for $2 \mathrm{~h}$ which was then extended to continuous treatment. The effluent after Fenton's treatment was passed to the settling tank from where the supernatant was passed to the second reactor in which ammonium-N and phosphate were converted into struvite by the addition of magnesium salts. This was followed by another settling tank where majority of struvite settled down. Then the chemically treated effluent was micro-filtered at low pressure by a flat sheet cross flow microfiltration module for the 
separation of struvite. Permeate of the first module was then passed to a second nanofiltration cross flow module for removal of all charged and non-charged particles following Donnan steric and sieving mechanisms [22].

\subsection{Analytics}

The ammonium- $\mathrm{N}$ content was determined using Orion 4 Star $\mathrm{pH}$ ISE bench-top ion meter using Orion Ammonia Electrode. The electrode was first calibrated using 10 and 100 ppm standard ammonium solution. COD and phosphate content were calculated by the standard procedures described in standard methods [23]. The analysis of COD was done in spectrophotometer by Thermo Scientific at the wavelength of $600 \mathrm{~nm}$. Total carbon and total inorganic carbon (TIC) were determined by TOC Analyzer (Aurora 1030 USA). In case of nanofiltration the percentage removal of contaminants (given by rejection, $\mathrm{R} \%$ ) were calculated using the initial concentration of the feed $\left(C_{i}\right)$ and the final concentration on permeate side $\left(\mathrm{C}_{\mathrm{f}}\right)$ using the Eq. 1 given below.

$\mathrm{R}(\%)=\left(1-\frac{\mathrm{C}_{\mathrm{f}}}{\mathrm{C}_{\mathrm{i}}}\right) \times 100$

\section{RESULTS AND DISCUSSION}

\subsection{Fenton's Treatment for COD Removal}

Hydrogen peroxide is strong oxidizing agent. At low $\mathrm{pH}, \mathrm{Fe}^{2+}$ helps in the generation of hydroxyl radicals which is known to be the second most powerful oxidizing agent. It acts as a catalyst for the removal of COD. Fenton oxidation may be represented by the following equations (Zhang et al. 2013):

$$
\begin{aligned}
& \mathrm{H}_{2} \mathrm{O}_{2}+\mathrm{Fe}^{2+} \rightarrow \mathrm{Fe}^{3+}+\mathrm{OH}^{-}+\mathrm{OH}^{\cdot} \\
& \mathrm{H}_{2} \mathrm{O}_{2}+\mathrm{Fe}^{3+} \rightarrow \mathrm{Fe}^{2+}+\mathrm{H}^{+}+\mathrm{HO}_{2}^{\cdot} \\
& \mathrm{RH}+\mathrm{OH}^{\cdot} \rightarrow \mathrm{H}_{2} \mathrm{O}+\mathrm{R}^{\cdot}
\end{aligned}
$$

However increased $\mathrm{H}_{2} \mathrm{O}_{2}$ concentrations led to autodecomposition of residual $\mathrm{H}_{2} \mathrm{O}_{2}$ according to Eq. 5-7 [13]. Furthermore higher concentrations of organic matter favor regeneration of $\mathrm{Fe}^{2+}$ (Eq. 8) while as higher concentration of $\mathrm{Fe}^{2+}$ favors scavenging reaction (Eq. 9)

$$
\begin{aligned}
& \mathrm{OH}^{\cdot}+\mathrm{H}_{2} \mathrm{O}_{2} \rightarrow \mathrm{HO}_{2}^{\cdot}+\mathrm{H}_{2} \mathrm{O} \\
& 2 \mathrm{HO}_{2}^{\cdot} \rightarrow \mathrm{H}_{2} \mathrm{O}_{2}+\mathrm{O}_{2} \\
& \mathrm{HO}_{2}^{\cdot}+\mathrm{OH}^{\cdot} \rightarrow \mathrm{H}_{2} \mathrm{O}+\mathrm{O}_{2} \\
& \mathrm{R}^{\cdot}+\mathrm{Fe}^{3+} \rightarrow \mathrm{R}^{+}+\mathrm{Fe}^{2+} \\
& \mathrm{Fe}^{2+}+\mathrm{OH}^{\cdot} \rightarrow \mathrm{Fe}^{3+}+\mathrm{OH}^{-}
\end{aligned}
$$

COD was removed by Fenton's reagent ( $\mathrm{FeSO}_{4} \cdot 7 \mathrm{H}_{2} \mathrm{O}$ and $\mathrm{H}_{2} \mathrm{O}_{2}$ ) by optimizing different concentrations of ferrous sulphate, hydrogen peroxide, $\mathrm{pH}$ and temperature. Lower $\mathrm{pH}$ favours oxidation process but struvite precipitation requires higher $\mathrm{pH}$. Hence using $\mathrm{pH}$ lower than 4 will increase the cost of chemicals being used during the process. Furthermore, the study is being carried out under psychrophilic conditions, hence lower temperature range is being chosen The range of different parameters were fixed as temperature $\left(12.5-22.5^{\circ} \mathrm{C}\right), \mathrm{pH}(4-8), \mathrm{Fe}^{2+} / \mathrm{H}_{2} \mathrm{O}_{2}$ (0.025-0.125 g/l) and $\mathrm{H}_{2} \mathrm{O}_{2}(0.50-2.50)$ with a reaction time of $2 \mathrm{~h}$ based on various data reported in literature and are incorporated in the design as given in Table $\mathbf{2}$.

Optimization was done using response surface methodology (RSM) of Design Expert software. In this statistical method, process optimization is carried out based on the input data provided. Response surface optimization is carried out in three steps i.e. statistical design of experiments, estimation of coefficients of mathematical model and examination of adequacy of model [24]. The experimental design used in the present study was a central composite design (CCD) which fits a model by least square technique [15]. CCD is applicable for fitting a quadratic surface and the optimization as well as interaction of parameters is achieved by least number of experiments [25]. It consists of $2^{k}$ factorial runs, $2 k$ axial runs and $k_{c}$ central runs, where $k$ denotes the number of variables. For four factors the total number of experiments was calculated from Eq. 10 as:

$$
\mathrm{N}=2^{\mathrm{k}}+2 \mathrm{k}+\mathrm{k}_{\mathrm{c}}=2^{4}+2 \times 4+6=30
$$

From the fit summary section in design, the $F$ value of 45.0 and $P(<0.0001)$ value of less than 0.05 were obtained for COD removal respectively indicating that the model terms are significant. Adequacy of the model is shown with the help of diagnostic checking tests provided by analysis of variance (ANOVA). The 
Table 2: Experimental Response Under Suggested Operating Conditions by CCD

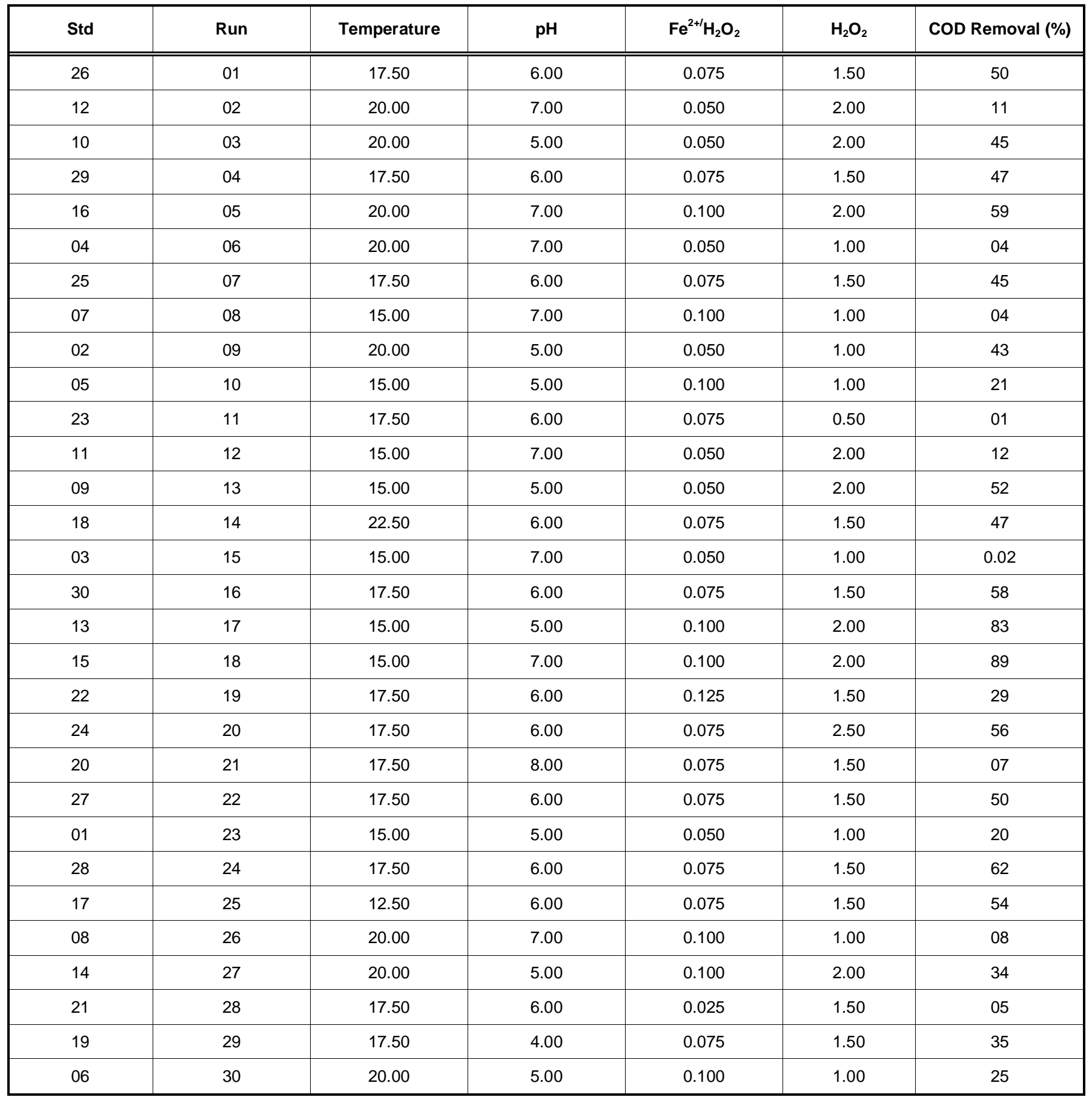

Table 3: Statistical Parameters Obtained from ANOVA for Regression Model

\begin{tabular}{|c|c|c|c|c|c|}
\hline Response & $\mathbf{R}^{2}$ & Adjusted $^{2}$ & $\mathbf{C V}(\%)$ & SD & AP \\
\hline \hline COD Removal & 0.98 & 0.96 & 9.7 & 0.5 & 26.4 \\
\hline
\end{tabular}

CV: Coefficient of variance; SD: Standard deviation; AP: adequate precision.

relationship between the output and the input parameters is given in terms of coded factors represented by Eq. 11 and the statistical parameters obtained are given below in Table 3. 


$$
\begin{aligned}
\operatorname{sqrt}(\% \text { COD Removal })= & +7.20-0.062 \times \mathrm{A}-1.05 \times \mathrm{B}+0.79 \times \mathrm{C} \\
& +1.59 \times \mathrm{D}+0.13 \times \mathrm{A} \times \mathrm{B}-0.44 \times \mathrm{A} \times \mathrm{C} \\
& -0.68 \times \mathrm{A} \times \mathrm{D}+0.84 \times \mathrm{B} \times \mathrm{C}+0.54 \times \mathrm{B} \times \mathrm{D} \\
& +0.63 \times \mathrm{C} \times \mathrm{D}+2.749 \mathrm{E}-003 \times \mathrm{A}^{2} \\
& -0.70 \times \mathrm{B}^{2}-0.82 \times \mathrm{C}^{2}-0.71 \times \mathrm{D}
\end{aligned}
$$

where $A, B, C$ and $D$ are temperature, $\mathrm{pH}, \mathrm{Fe}^{2+/} \mathrm{H}_{2} \mathrm{O}_{2}$ and $\mathrm{H}_{2} \mathrm{O}_{2}$ respectively.

The efficiency of the model was evaluated on the basis of regression and standard deviation value. The value of $R^{2}$ closer to unity and smaller standard deviation implies more accurate prediction of response by the model. The value of adjusted $R^{2}(0.96)$ and predicted $R^{2}(0.9)$ are in agreement with each other implying that the model is significant. The plot of experimental versus calculated values were plotted in Figure 2 in which the clustering of points along the diagonal indicated the ability of the model to predict the experiment. The coefficient of variance is the ratio of standard error of estimate to the mean value of observed response (as percentage). It gives the measure of reproducibility of model and should generally be not more than $10 \%$ for a model to be considered reasonably reproducible. The CV value of 9.7 in our present experiment indicated a good reproducibility. The adequate precision value is the measure of signal to noise ratio and should be desirably more than 4 [26]. We obtained AP ratio of 26.4. Hence the model can be used to navigate the design space.

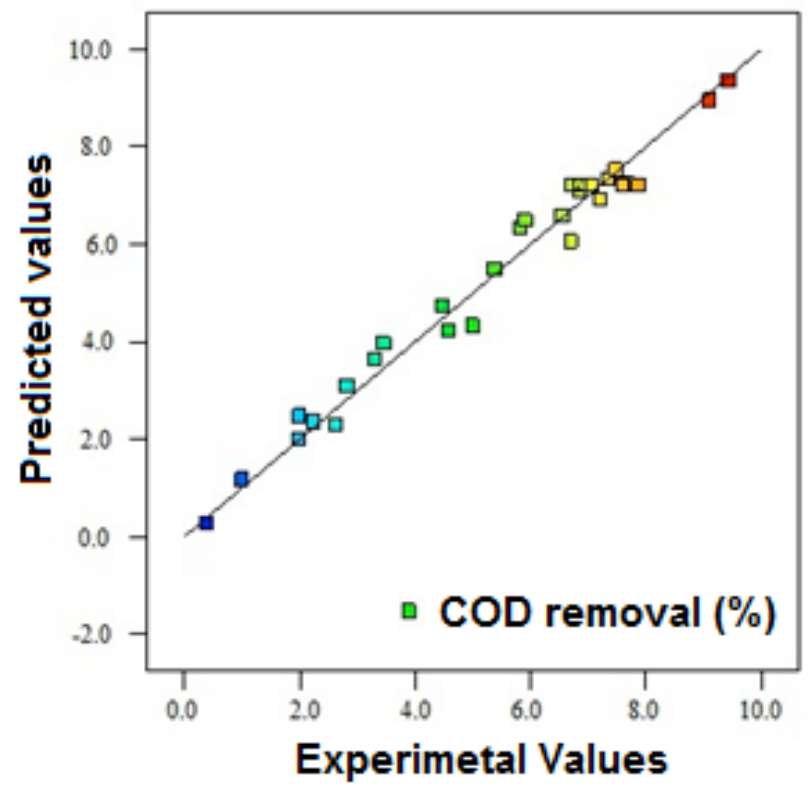

Figure 2: A plot of experimental versus predicted values for COD removal.
For better understanding of the results, the predicted models are represented as three dimensional response surface plots as given in Figure 3. As a general trend, it was observed that the temperature did not have much effect on the removal of COD. However the ratio of $\mathrm{Fe}^{2+} / \mathrm{H}_{2} \mathrm{O}_{2}$ and the concentration of $\mathrm{H}_{2} \mathrm{O}_{2}$ played an important role in COD removal. The maximum removal was at a $\mathrm{pH}$ of around 6.0 and both increase or decrease in $\mathrm{pH}$ led to reduction in the removal percentage of COD. With the increase in $\mathrm{Fe}^{2+}$, COD removal increased due to more generation of hydroxyl ions. Iron also acts as a coagulant and hence all small particles coagulated and precipitated out. In this way iron helps in coagulation process also.

The criteria were selected for the optimization of parameters in the selected range for the maximum removal of COD. From the set of suggested solutions, the solution chosen was $\mathrm{Fe}^{2+/} \mathrm{H}_{2} \mathrm{O}_{2}$ ratio of 0.10 and $\mathrm{H}_{2} \mathrm{O}_{2}$ concentration of $1.99 \mathrm{~g} / \mathrm{l}$ at $\mathrm{pH}$ of 6.28 and temperature of $15^{\circ} \mathrm{C}$ by which a maximum $\mathrm{COD}$ removal of $96 \%$ was obtained by optimization. The model predicted values were rechecked at same conditions and the COD removal was found to be close to the model value.

\subsection{Removal of Ammonium-N and Phosphate as Struvite}

After Fenton's treatment, ammonium-N and phosphate were precipitated out as magnesium ammonium phosphate (struvite) in struvite formation unit. Struvite is formed by the following chemical reaction expressed by Eq. 12 [27].

$$
\mathrm{Mg}^{2+}+\mathrm{NH}_{4}^{+}+\mathrm{PO}_{4}^{3-} \Leftrightarrow \mathrm{MgNH}_{4} \mathrm{PO}_{4} \cdot 6 \mathrm{H}_{2} \mathrm{O} \downarrow
$$

When struvite is formed, hydrogen ions are released into the solution causing decrease in $\mathrm{pH}$ as shown by Eq. 13. At low pH these hydrogen ions inhibit struvite formation while at high $\mathrm{pH}$ other precipitates were formed instead of struvite. It was found that a $\mathrm{pH}$ value of 9.0 maintained using $\mathrm{NaOH}$ and $\mathrm{HCl}$ solution gave better recovery of struvite.

$$
\begin{aligned}
& \mathrm{Mg}^{2+}+\mathrm{NH}_{4}^{+}+\mathrm{HPO}_{4}^{2-}+6 \mathrm{H}_{2} \mathrm{O} \\
& \Leftrightarrow \mathrm{MgNH}_{4} \mathrm{PO}_{4} \cdot 6 \mathrm{H}_{2} \mathrm{O} \downarrow+\mathrm{H}^{+}
\end{aligned}
$$

Different salts of magnesium were used such as $\mathrm{MgCl}_{2} \cdot 6 \mathrm{H}_{2} \mathrm{O}, \mathrm{MgO}$ and $\mathrm{MgSO}_{4} \cdot 7 \mathrm{H}_{2} \mathrm{O}$ at different molar ratios of $\mathrm{Mg}^{2+}$ to find out the best chemical for maximum precipitation of ammonium-N and phosphate. Furthermore, there was a rapid decrease in 
(a)

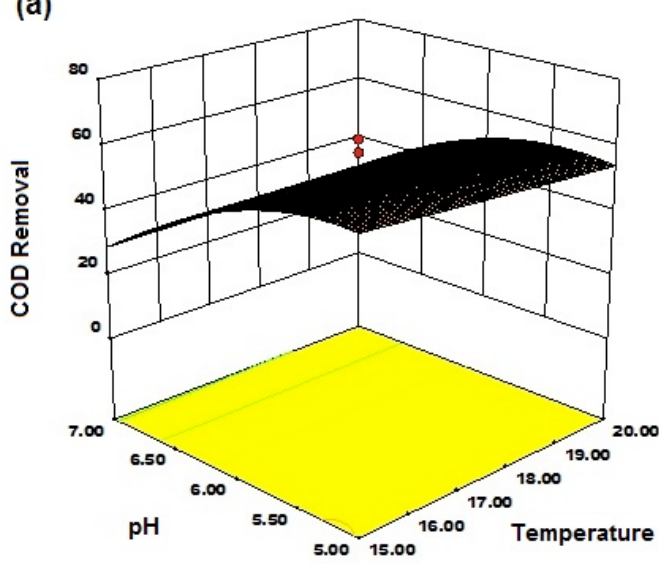

$\mathrm{H}_{2} \mathrm{O}_{2}=1.5 \mathrm{~g} / \mathrm{l}$ and $\mathrm{Fe}^{2+} / \mathrm{H}_{2} \mathrm{O}_{2}=0.075$

(c)

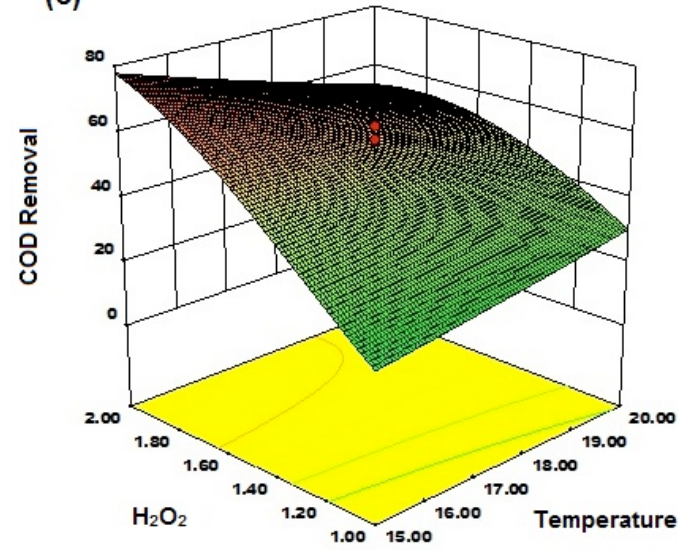

$\mathrm{pH}=6.00$ and $\mathrm{Fe}^{2+/} \mathrm{H}_{2} \mathrm{O}_{2}=0.075$

(e)

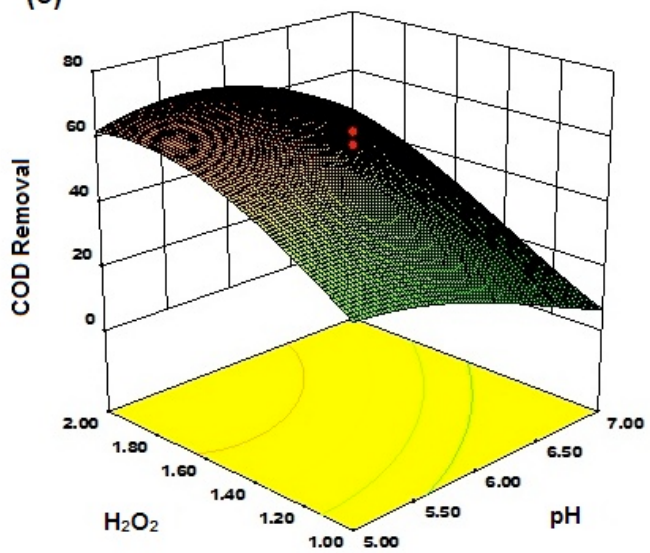

Temperature $=17.50^{\circ} \mathrm{C}$ and $\mathrm{Fe}^{2+} / \mathrm{H}_{2} \mathrm{O}_{2}=0.075$

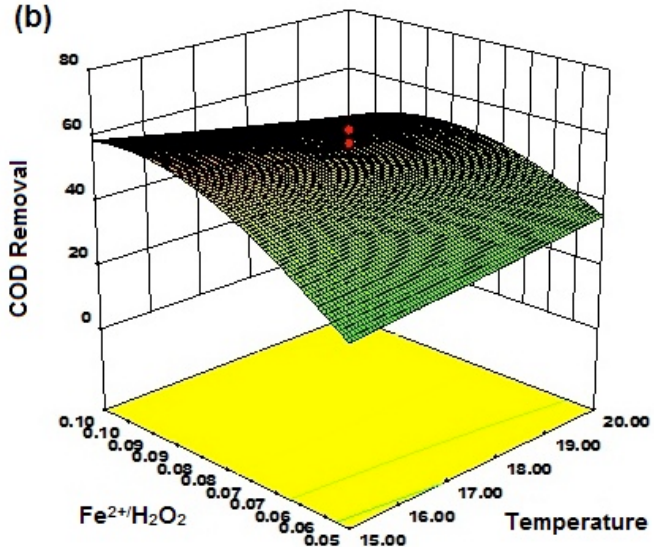

$\mathrm{pH}=6.0$ and $\mathrm{H}_{2} \mathrm{O}_{2}=1.5 \mathrm{~g} / \mathrm{l}$

(d)

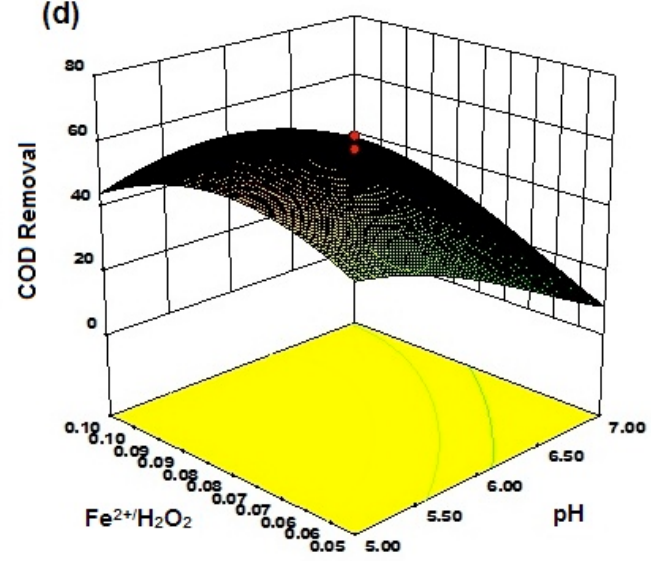

Temperature $=17.50^{\circ} \mathrm{C}$ and $\mathrm{H}_{2} \mathrm{O}_{2}=1.5 \mathrm{~g} / \mathrm{l}$

(f)

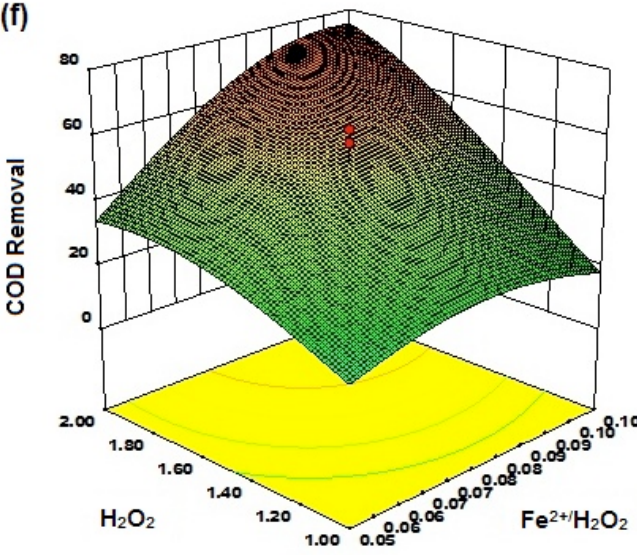

Temperature $=17.50^{\circ} \mathrm{C}$ and $\mathrm{pH}=6.00$

Figure 3: Response surface optimization showing COD removal (\%) with change in pH, temperature, $\mathrm{H}_{2} \mathrm{O}_{2}$ and $\mathrm{Fe}^{2+1} \mathrm{H}_{2} \mathrm{O}_{2}$.

$\mathrm{NH}_{4}{ }^{+}-\mathrm{N}$ and phosphate concentrations in wastewater and the effect was more remarkable for higher magnesium concentration till a molar ratio of $1: 1: 1$ for $\mathrm{MgCl}_{2} \cdot 6 \mathrm{H}_{2} \mathrm{O}$, phosphate and $\mathrm{NH}_{4}{ }^{+}-\mathrm{N}$. The literature also indicated the same results [20]. $\mathrm{MgCl}_{2} \cdot 6 \mathrm{H}_{2} \mathrm{O}$ and $\mathrm{Na}_{2} \mathrm{HPO}_{4} \cdot 12 \mathrm{H}_{2} \mathrm{O}$ react with $\mathrm{NH}_{4}{ }^{+}-\mathrm{N}$ resulting in salt formation as given by Eq.14. 
$\mathrm{MgCl}_{2} \cdot 6 \mathrm{H}_{2} \mathrm{O}+\mathrm{NH}_{4}^{+}+\mathrm{Na}_{2} \mathrm{HPO}_{4} \cdot 12 \mathrm{H}_{2} \mathrm{O}$

$\Leftrightarrow \mathrm{MgNH}_{4} \mathrm{PO}_{4} \cdot 6 \mathrm{H}_{2} \mathrm{O} \downarrow+2 \mathrm{NaCl}+12 \mathrm{H}_{2} \mathrm{O}+\mathrm{H}^{+}$

The salt production results in increase of salinity and conductivity of water which is successfully removed by the nanofiltration membrane. $\mathrm{NH}_{4}{ }^{+}-\mathrm{N}$ removal follows first order kinetics with the first order rate equation as given by Eq. 15 where $C_{0}$ is the initial concentration of reactant and $C_{e}$ is the equilibrium concentration indicating that the reaction was complete.

$-\ln \frac{\left(C-C_{e}\right)}{\left(C_{0}-C_{e}\right)}=k t$
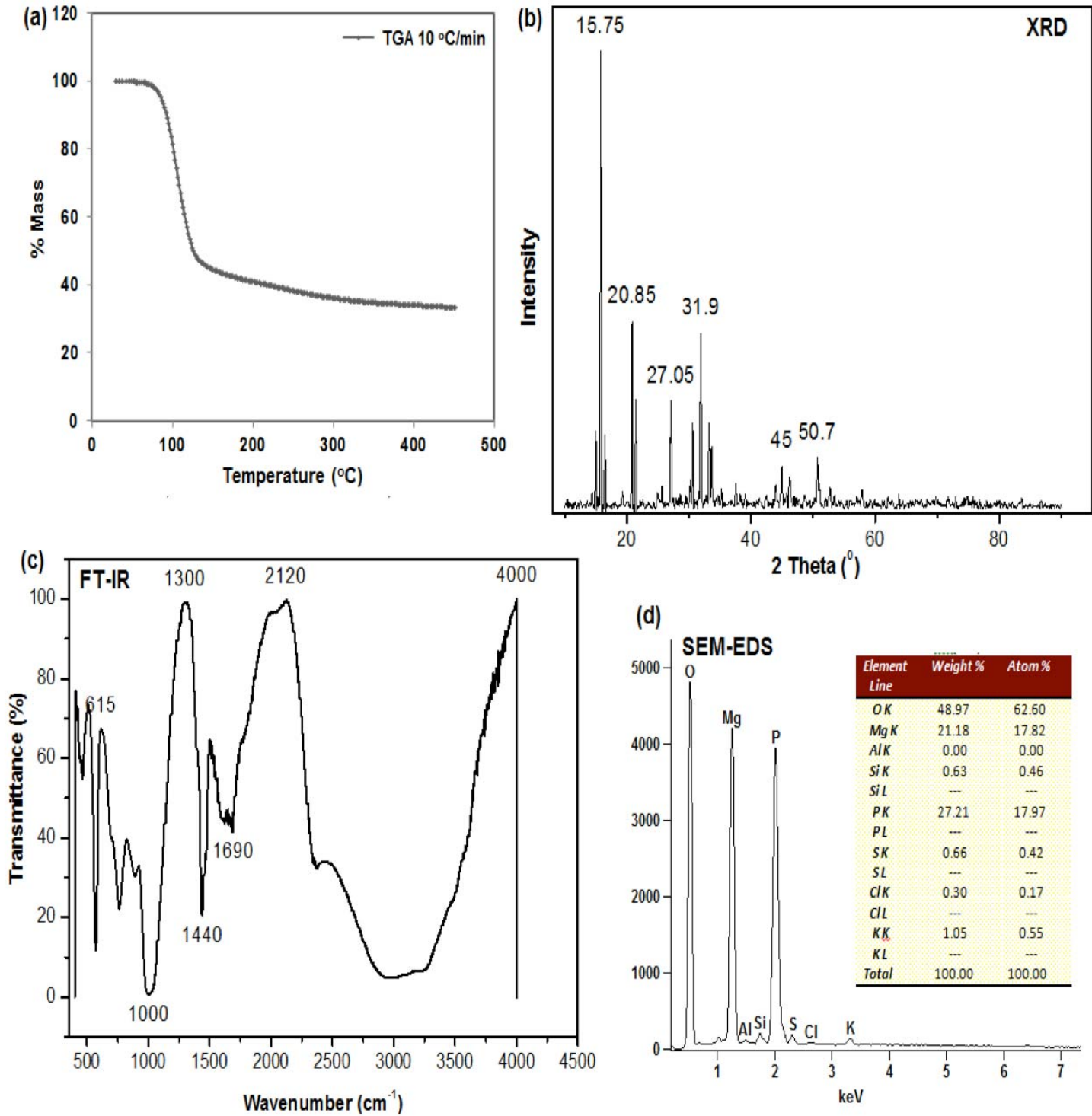

Figure 4: Surface characterization analysis of struvite. (a) TGA-DTGA; (b) XRD analysis; (c) FT-IR analysis; (d) SEM-EDS analysis. 
and SEM profiles are similar to that of struvite as reported elsewhere. The FTIR showed that after TGA the water stretching broad band is at $3405-3650 \mathrm{~cm}^{-1}$.

\subsection{Membrane Separation}

The struvite formed was separated out with the help of cross flow microfiltration membrane module operated at low pressure of around 2 bars. The PVDF microfiltration membrane module recovered more than $99 \%$ of struvite formed. Maximum flux of $710 \mathrm{I} \mathrm{m}^{-2} \mathrm{~h}^{-1}$ was obtained at 2 bar transmembrane pressure (TMP) and cross flow velocity (CFV) of $1.25 \mathrm{~m} / \mathrm{s}$. Initially the flux is declined due to precipitation of struvite and due to cake layer formation but it reaches a steady value after certain time. It was also observed that the increase in concentration of struvite caused decrease in flux.

The concentration of ions in the effluent was increased due to addition of ions and salts during struvite formation. Thus nanofiltration was employed for the removal of these trace elements and remaining ammonium and phosphate ions and COD. Hence it acts as a final polishing step for potential reusable water. We analyzed four different polyamide composite membranes (NF1, NF2, NF3 and NF20) in cross flow membrane module. A plot of permeate flux versus transmembrane pressure (as shown in Figure 5) revealed that with increase in transmembrane pressure the flux also increases and varies linearly for all nanofiltration membranes. At a transmembrane pressure of 16 bar the NF2 membrane has highest flux (295 $\mathrm{I} \mathrm{m}^{-2} \mathrm{~h}^{-1}$ ) while NF1 membrane has lowest flux

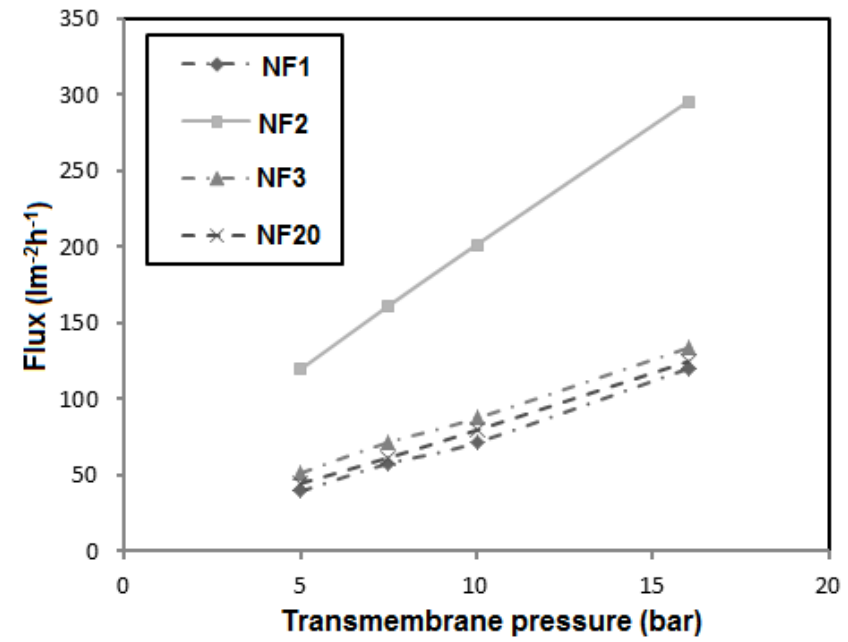

Figure 5: Change in flux with respect to transmembrane pressure for nanofiltration membrane at a cross flow rate of $800 \mathrm{I} \mathrm{h}^{-1}$. $\left(120 \mathrm{I} \mathrm{m}^{-2} \mathrm{~h}^{-1}\right)$. This is because NF2 membrane has more pore radius $(0.57 \mathrm{~nm})$ as compared to NF1 membrane $(0.53 \mathrm{~nm})$. The NF20 and NF3 membranes has intermediate flux (125 and $134 \mathrm{I} \mathrm{m}^{-2} \mathrm{~h}^{-}$ ${ }^{1}$ respectively) as their pore radius was in between that of NF1 and NF2 (0.54 and $0.55 \mathrm{~nm}$ respectively).

The effect of transmembrane pressure on the rejection of TDS, conductivity and salinity are given in Figure 6. It was observed that with the increase in transmembrane pressure the rejection also increased from $55.5 \%$ to $87 \%, 62.5 \%$ to $88.4 \%$ and $68.5 \%$ to $95.8 \%$ for TDS, conductivity and salinity respectively by NF1 membrane. It was also observed that there was no improvement in rejection of ions beyond operating pressure of 16 bars.

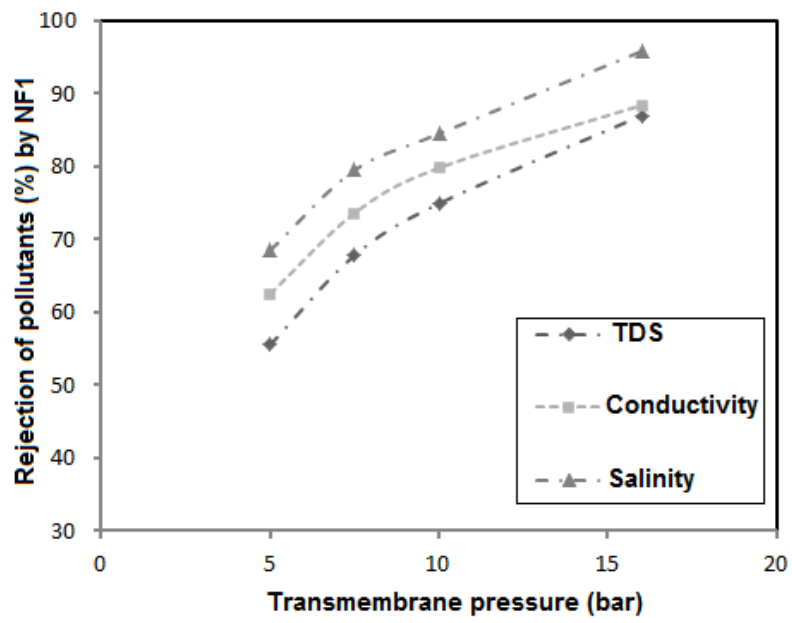

Figure 6: Effect of pressure on the percentage rejection of TDS, conductivity and salinity.

The two transport mechanisms for nanofiltration are solution diffusion mechanism and size exclusion mechanism. In case of solution diffusion mechanism, transport occurs only by diffusion. With the increase in transmembrane pressure the solvent flux increases without increasing the solute flux because the solute flux and solvent flux are uncoupled. Hence when we increase transmembrane pressure the pure water flux is increased while the solute flux remains constant. However in case of size exclusion mechanism the separation is done on the basis of relative size of membrane pore and solute [28]. The solute particles having size larger than the pore size of membrane do not pass through and form a cake layer while solvent and the solute with smaller size pass through the membrane. Donnan exclusion also plays an important role in separation of solute by nanofiltration. The nanofiltration membranes carry charge and hence they 
attract the solutes with opposite charge (counter-ions) and repel the solutes with similar charge (co-ions).

It was observed that the pore size of polyamide nanofiltration membrane varies with the solution $\mathrm{pH}$. The osmotic pressure and ionic strength increases at higher $\mathrm{pH}$, thus reducing the membrane permeability. Furthermore the functional groups present at the surface of membrane are deprotonated [29]. This leads to increase in the thickness of diffuse double layer of charged functional groups. Hence it reduces the relative size of membrane pore and increases the rejection of charged solute.

The concentration of COD and TDS were increased in the retentate side of the nanofiltration separation process. COD was initially treated up to $96 \%$ with response surface optimized Fenton's reagent before membrane separation process. Then ammonium- $\mathrm{N}$ was recovered by chemical precipitation methods to form the struvite. These two chemical processes have increased the TDS concentration due to increase in ion concentration. These ions were separated by nanofiltration methods. It was calculated that $75 \mathrm{mg} / \mathrm{L}$ COD and 29,300 mg/L TDS was found in the concentrate after nanofiltration membrane separation process when $70 \%$ feed wastewater was recovered with initial volume of $30 \mathrm{~L}$. The nanofiltration concentrate periodically transferred to the feed tank for chemical treatment and then membrane separation.

\subsection{Fouling}

The use of cross flow membrane module reduced the fouling of the membrane by the sweeping action of wastewater on the membrane. The retentate was recirculated in the feed tank. It was found that fouling was not significant during long hours of operation. The flux and rejection were did not decline effectively. However, build-up of concentration polarization is very much dependent on mode of operation and types of membrane modules used and hydrodynamics maintained. If the membrane module is operated in dead-end mode, concentration polarization builds up rapidly. Fouling can be avoided to a large extent by choosing proper module like flat-sheet cross-flow module where sweeping action of the fluid on membrane surface reduces the possibility of concentration polarization. However fouling can't be avoided completely, so after every $25 \mathrm{~h}$ PVDF MF membrane and $92 \mathrm{~h} \mathrm{NF}$ membranes were got fouled. The cleaning of fouled membrane after filtration experiments was done by using deionized water, $0.1 \mathrm{~N}$ $\mathrm{NaOH}, 0.01 \mathrm{~N} \mathrm{NaOCl}$ and $0.01 \mathrm{M} \mathrm{HNO}_{3}$. The treatment time may vary from types of membranes (MF or NF) and it may take 30- 60 min time. Chemical cleaning is the most widely practiced method for reducing the fouling problem with an acidic, alkaline and alkali oxidizing agents to obtain the flux recovery [30].

\subsection{Economic Analysis}

The cost estimation was carried out for a plant of capacity $50,000 \mathrm{l} /$ day at a flux of $120 \mathrm{I} \mathrm{m}^{-2} \mathrm{~h}^{-1}$ by NF1 membrane at 15 bar pressure. Considering 16 working hours in a day the membrane area required was $27 \mathrm{~m}^{2}$ using Eq. 17.

Membrane area required $=\frac{\text { Plant capacity }\left(1 \text { day }^{-1}\right)}{\text { Flux obtained }\left(1 \mathrm{~m}^{-2} \text { day }^{-1}\right)}$

Considering one module with membrane surface area of $0.5 \mathrm{~m}^{2}$ the number of modules $(\mathrm{n})$ required will be 54 given by Eq. 18 .

Number of modules $(n)=\frac{\text { Required membrane area }\left(\mathrm{m}^{2}\right)}{\text { Membrane area per module }\left(\mathrm{m}^{2}\right)}$

The capital cost involves the civil investment for the installation of building, mechanical engineering cost for the cost of tanks, pipes and valves, electro-technical cost for the cost of rotameter, pressure gauge, pumps and $\mathrm{pH}$ probes and the membrane module cost. The operating cost includes the consumption cost of electricity, membranes, labor and chemicals. The components of capital cost were calculated from the following equations (Eq. 19 - Eq. 22). The overall capital and operating cost are given below in Tables 4 and 5.

Civil Investment $(\$)=102 \mathrm{Q}_{\mathrm{F}}^{0.21}+263 \mathrm{n}$

Mechanical Engineering $(\$)=1039 \mathrm{Q}_{\mathrm{F}}^{0.14}+174 \mathrm{n}$

Electrotechnical Investment $(\$)=1.75 \times 10^{3}+39 \mathrm{PQ}_{\mathrm{F}}^{0.43}$

Membrane module cost $(\$)=400 n$

The annualized capital and operating costs are to be calculated for the economic evaluation of hybrid treatment plant which is calculated for $Q \mathrm{~m}^{3}$ year $^{-1}$ using Eq. 23 and Eq. 24 [31]. 
Table 4: Capital Cost Involved for Hybrid Wastewater Treatment Plant of Capacity 50,000 L/day

\begin{tabular}{|c|c|c|}
\hline Cost & Item name/character & Total cost (\$) \\
\hline \hline Civil investment & Treatment room & 75000 \\
\hline Mechanical engineering & (i) 5 Tanks $\left(50 \mathrm{~m}^{3}\right)$ & 3000 \\
\cline { 2 - 3 } & (ii) Pipe (300 m) & 3000 \\
\cline { 2 - 3 } & (iii) Valves (3000) & 1200 \\
\hline \multirow{2}{*}{ Electro-technical investment } & (i) 2 Rotameters & 160 \\
\cline { 2 - 3 } & (ii) 2 Pressure Gauges & 40000 \\
\cline { 2 - 3 } & (iii) 2 Pumps & 150 \\
\cline { 2 - 3 } & (iv) 3 pH probes & 43200 \\
\hline
\end{tabular}

Table 5: Operating Cost Involved for Hybrid Wastewater Treatment Plant of Capacity 50,000 L/day

\begin{tabular}{|c|c|c|}
\hline Cost & Item name/character & Total cost $(\$ /$ year) \\
\hline \hline Electricity & Electricity consumption 33000 units/year & 3000 \\
\hline Membrane & $27 \mathrm{~m}^{2} \mathrm{NF} 1$ and $27 \mathrm{~m}^{2} \mathrm{MF}$ membranes (life of 6 months) & 2700 \\
\hline Labor & $1 \mathrm{Labor}$ with salary of $\$ 100 / \mathrm{month}$ & 1200 \\
\hline Chemicals & Cost of Fenton's reagents $\left(\mathrm{H}_{2} \mathrm{O}_{2}\right.$ and $\left.\mathrm{FeSO}_{4} \cdot 7 \mathrm{H}_{2} \mathrm{O}\right), \mathrm{NH}_{4} \mathrm{Cl}, \mathrm{MgSO}_{4}, \mathrm{NaOH}$ and $\mathrm{HCl}$ & 7850 \\
\hline
\end{tabular}

Annualized capital cost $=\frac{(\text { Total capital cost } \times \text { CRF })}{Q_{F}}$

Annualized operating cost $\left(\$ \mathrm{~m}^{-3}\right)=\frac{\text { (Total operating cost) }}{\mathrm{Q}_{\mathrm{F}}}$

where water production rate $\left(Q_{F}\right)$ is calculated as

$\mathrm{Q}_{\mathrm{F}}=\left(\frac{50000 \times 365}{1000}\right)=18250 \mathrm{~m}^{3}$ year $^{-1}$

and capital recovery factor (CRF) is calculated as

$\mathrm{CRF}=\left(\frac{\mathrm{i}(1+\mathrm{i})^{\mathrm{n}}}{(1+\mathrm{i})^{\mathrm{n}+1}-1}\right)$

where $n$ is project life and $i$ is interest rate. A project life of 15 years with annual interest rate of $5 \%$ is reasonable for high quality stainless steel membrane modules [32]. The CRF value calculated is 0.088 .

Annualized capital cost $=\frac{113210 \times 0.088}{18250}=0.545$
Annualized operating cost $\left(\$ \mathrm{~m}^{-3}\right)=\frac{14750}{18250}=0.808$

On adding capital and operating costs, the annualized cost of production of $1 \mathrm{~m}^{3}$ of reusable water stands at around $\$ 1.4$ which seems to be quite affordable to the affected people. This estimate follows standard scale up principle though for a full scale plant, the cost may vary marginally.

\section{CONCLUSION}

Conventional biological treatment plants for municipal wastewater face difficulty at low temperatures due to impeded microbial growth. The investigated hybrid treatment scheme is characterized by high degree of separation of nutrients from wastewater even at very low temperature and is quite fast where the treatment period of days in conventional scheme turns into a matter of hours. Optimized Fenton's treatment using Response Surface Methodology of Design Expert software (8.0) helps achieve high degree of removal of the nutrients in the form of useful struvite fertilizer adding economy to the overall process. The formation of struvite is confirmed 
and characterized by FTIR, XRD and SEM analysis. In low temperature municipal wastewater treatment, the proposed scheme may be considered as a fast, green and economically attractive novel approach.

\section{REFERENCES}

[1] Sperling MV, Freire VH, Chernicharo CAL. Performance evaluation of a UASB - activated sludge system treating municipal wastewater. Water Science and Technology 2001; 43(11): 323-8.

[2] Luca GD, Sacchetti R, Leoni E, Zanetti F. Removal of indicator bacteriophages from municipal wastewater by a fullscale membrane bioreactor and a conventional activated sludge process: Implications to water reuse. Bioresource Technology 2013; 129: 526-531. http://dx.doi.org/10.1016/j.biortech.2012.11.113

[3] Lin SH, Cheng KW. A new sequencing batch reactor for treatment of municipal sewage wastewater for agricultural reuse. Desalination 2001; 133: 41-51.

http://dx.doi.org/10.1016/S0011-9164(01)00081-9

[4] Guo JH, Peng YZ, Wang SY, Zheng YN, Huang HJ, Ge SJ. Effective and robust partial nitrification to nitrite by real-time aeration duration control in an SBR treating domestic wastewater. Process Biochemistry 2009; 44: 979-985. http://dx.doi.org/10.1016/j.procbio.2009.04.022

[5] Chu L, Li S. Filtration capability and operational characteristics of dynamic membrane bioreactor for municipal wastewater treatment. Separation and Purification Technology 2006; 51: 173-179. http://dx.doi.org/10.1016/j.seppur.2006.01.009

[6] Monclus H, Sipma J, Ferrero G, Roda IR, Comas J. Biological nutrient removal in an MBR treating municipal wastewater with special focus on biological phosphorus removal. Bioresource Technology 2010; 101: 3984-3991. http://dx.doi.org/10.1016/..biortech.2010.01.038

[7] Lin H, Chen J, Wang F, Ding L, Hong H. Feasibility evaluation of submerged anaerobic membrane bioreactor for municipal secondary wastewater treatment. Desalination 2011; 280: 120-126

http://dx.doi.org/10.1016/j.desal.2011.06.058

[8] Chon K, Cho J, Shon HK. Fouling characteristics of a membrane bioreactor and nanofiltration hybrid system for municipal wastewater reclamation. Bioresource Technology 2013; 130: 239-247.

http://dx.doi.org/10.1016/j.biortech.2012.12.007

[9] Devi R, Dahiya RP. COD and BOD removal from domestic wastewater generated in decentralized sectors. Bioresource Technology 2008; 99: 344-349.

http://dx.doi.org/10.1016/j.biortech.2006.12.017

[10] Guida M, Mattei M, Rocca CD, Melluso G, Meric S. Optimization of alum-coagulation/flocculation for COD and TSS removal from five municipal wastewater. Desalination 2007; 211: 113-127. http://dx.doi.org/10.1016/j.desal.2006.02.086

[11] Ismail IM, Fawzy AS, Monem NMA, Mahmoud MH, ElHalwany MA. Combined coagulation flocculation pretreatment unit for municipal wastewater. Journal of Advanced Research 2012; 3: 331-336. http://dx.doi.org/10.1016/j.jare.2011.10.004

[12] Zhang G, Qin L, Meng Q, Fan Z, Wu D. Aerobic SMBR/reverse osmosis system enhanced by Fenton oxidation for advanced treatment of old municipal landfill leachate. Bioresource Technology 2013; 142: 261-268. http://dx.doi.org/10.1016/j.biortech.2013.05.006

[13] Bautista P, Mohedano AF, Gilarranz MA, Casas JA, Rodriguez JJ. Application of Fenton oxidation to cosmetic wastewaters treatment. Journal of Hazardous Materials 2007; 143: 128-134.

http://dx.doi.org/10.1016/j.jhazmat.2006.09.004

[14] Badawy MI, Wahaab RA, El-Kalliny AS. Fenton-biological treatment processes for the removal of some pharmaceuticals from industrial wastewater. Journal of Hazardous Materials 2009; 167: 567-574.

http://dx.doi.org/10.1016/j.jhazmat.2009.01.023

[15] Ahmadi M, Vahabzadeh F, Bonakdarpour B, Mofarrah E, Mehranian M (2005) Application of the central composite design and response surface methodology to the advanced treatment of olive oil processing wastewater using Fenton's peroxidation. Journal of Hazardous Materials 2005; 123: 187195. http://dx.doi.org/10.1016/j.jhazmat.2005.03.042

[16] Song YH, Qiu GL, Yuan P, Cui XY, Peng JF, Zeng P, Duan L, Xiang LC, Qian F. Nutrients removal and recovery from anaerobically digested swine wastewater by struvite crystallization without chemical additions. Journal of Hazardous Materials 2011; 190: 140-149.

http://dx.doi.org/10.1016/.j.jhazmat.2011.03.015

[17] Capdevielle A, Sykorova E, Biscans B, Beline F, Daumer ML. Optimization of struvite precipitation in synthetic biologically treated swine wastewater-Determination of the optimal process parameters. Journal of Hazardous Materials 2013; 244-245: 357-369.

http://dx.doi.org/10.1016/j.jhazmat.2012.11.054

[18] Wu Y, Zhou S. Improving the prediction of ammonium nitrogen removal through struvite precipitation. Environmental Science and Pollution Research 2012; 19: 347-360.

http://dx.doi.org/10.1007/s11356-011-0520-6

[19] Kumar R, Pal P. A membrane-integrated advanced scheme for treatment of industrial wastewater: Dynamic modeling towards scale up. Chemosphere 2013a; 92: 1375-1382. http://dx.doi.org/10.1016/j.chemosphere.2013.05.006

[20] Bunani S, Yorukoglu E, Sert G, Yuksel U, Yuksel M, Kabay N. Application of nanofiltration for reuse of municipal wastewater and quality analysis of product water. Desalination 2013; 315: 33-36. http://dx.doi.org/10.1016/i.desal.2012.11.015

[21] Zeng S, Chen J, Fu P. Strategic Zoning for Urban Wastewater Reuse in China. Water Resources Management 2008; 22: 1297-1309. http://dx.doi.org/10.1007/s11269-007-9226-4

[22] Kumar R, Bhakta P, Chakraborty S, Pal P. Separating cyanide from coke wastewater by cross flow Nanofiltration. Separation Science and Technology 2011; 46: 2119-2127. http://dx.doi.org/10.1080/01496395.2011.594479

[23] Clesceri LS, Greenberg AE, Eaton AD (ed). Standard Methods for the Examination of Water and Wastewater, twentieth edn. American Public Health Association (APHA), AWWA, WEF, Washington DC, USA; 1998.

[24] Myers RH, Montgomery DC. Response Surface Methodology: Process and Product Optimization Using Designed Experiments, first edn. John Wiley \& Sons Inc., New York; 1995.

[25] Hameed BH, Tan IAW, Ahmed AL. Optimization of basic dye removal by oil palm fiber based activated carbon using response surface methodology. Journal of Hazardous Materials 2008; 158: 324-332. http://dx.doi.org/10.1016/j.jhazmat.2008.01.088

[26] Beg Q, Sahai V, Gupta R. Statistical media optimization and alkaline protease production from Bacillus mojavensisin a bioreactor. Process Biochemistry 2003; 39: 203-209. http://dx.doi.org/10.1016/S0032-9592(03)00064-5

[27] Doyle JD, Parsons SA. Struvite formation, control and recovery. Water Resource 2002; 36(16): 3925-3940. http://dx.doi.org/10.1016/S0043-1354(02)00126-4 
[28] Teixeira MR, Rosa SM, Sousa V. Natural organic matter and disinfection by-products formation potential in water treatment. Water Resources Management 2011; 25: 30053015.

http://dx.doi.org/10.1007/s11269-011-9795-0

[29] Braghetta A, DiGiano FA, Ball WP. Nanofiltration of natural organic matter: $\mathrm{pH}$ and ionic strength effects. Journal of Environmental Engineering 1997; 123: 628-641. http://dx.doi.org/10.1061/(ASCE)0733-9372(1997)123:7(628)

[30] Kumar R, Pal P. Turning hazardous waste into value-added products: production and characterization of struvite from ammoniacal waste with new approaches. Journal of Cleaner Production 2013b; 43: 59-70. http://dx.doi.org/10.1016/j.jclepro.2013.01.001
[31] Chakrabortty S, Roy M, Pal P. Removal of fluoride from contaminated groundwater by cross flow nanofiltration: Transport modeling and economic evaluation. Desalination 2013; 313: 115-124

http://dx.doi.org/10.1016/j.desal.2012.12.021

[32] Roy $M$ and Chakraborty S. Developing a sustainable water resource management strategy for a fluoride-affected area: a contingent valuation approach. Clean Technologies and Environmental Policy 2014; 16: 341-349.

http://dx.doi.org/10.1007/s10098-013-0624-4 